Gorontalo Accounting Journal
https://jurnal.unigo.ac.id/index.php/gaj
Vol. 4, No. 2, October 2021
P-ISSN: 2614-2074, E-ISSN: 2614-2066
Gatolontialo
Nationally Accredited Journal, Decree No.36/E/KPT/2019 Sinta 4

\title{
Analisis Pengaruh Karakteristik Dewan Terhadap Manajemen Laba
}

\author{
Sukiantono Tang ${ }^{1}$, Shandy ${ }^{2}$ \\ 1,2 Universitas Internasional Batam/Batam/Indonesia \\ Email : sukiantono.tang@uib.edu ${ }^{1}$, shandd2621@gmail.com²,
}

Citation: Tang, S. \& Shandy. (2021). Analisis Pengaruh Karakteristik Dewan Terhadap Manajemen Laba. Gorontalo Accounting Journal 4(2), 159-173. DOI: 10.32662/gaj.v4i2.1707

\section{Artikel info}

Artikel history:

Received: 07-08-2021

Revised: 09-09-2021

Accepted: 05-10-2021
Abstract. This study aims to examine the effect of the characteristics of the board of directors on earnings management. Board characteristics are the most important part in the structure or governance of a company and government in limiting or preventing earnings management by a company manager. This study uses data from companies listed on the Indonesia Stock Exchange (IDX) which include annual reports from 2015 to 2019 except insurance companies, financial and banking institutions. Sampling of data was done by purposive sampling technique. This study combined the research object and one time dimension. This research was conducted using panel data regression test based on data that had been collected using SPSS and Eviews 10 software. The best model chosen for this research model was the Fixed Effect Model. The results showed that the board independent, board meeting, board of directors expertise, size of the audit committee, independent audit committee, audit committee meeting, audit committee expertise, leverage and big4 has no influence on the dependent variable earnings management. Then the size of the board of directors has a negative significant on earnings management. Meanwhile, company size and growth have a positive significant on earnings management.

Abstrak. Tujuan dari penelitian ini adalah untuk menguji pengaruh karakteristik dewan direksi terhadap manajemen laba. Karakteristik dewan merupakan bagian terpenting dalam struktur atau tata kelola suatu perusahaan dan pemerintahan untuk membatasi atau mencegah manajemen laba oleh manajer perusahaan. Penelitian ini menggunakan data dari perusahaan yang terdaftar di Bursa Efek Indonesia (BEI) dengan laporan tahunan dari tahun 2015 sampai dengan tahun 2019 kecuali perusahaan asuransi, lembaga keuangan dan perbankan. Pengambilan sampel data dilakukan dengan teknik purposive sampling. Penelitian ini menggabungkan objek penelitian dan satu dimensi waktu. Penelitian ini dilakukan dengan menggunakan uji regresi data panel berdasarkan data yang telah dikumpulkan menggunakan software SPSS dan Eviews 10. Model terbaik yang dipilih untuk model penelitian ini adalah Fixed Effect 


\begin{abstract}
Model. Hasil penelitian menunjukkan bahwa dewan independen, rapat dewan, keahlian dewan direksi, ukuran komite audit, komite audit independen, rapat komite audit, keahlian komite audit, leverage dan big4 tidak berpengaruh terhadap variabel dependen manajemen laba. Kemudian ukuran dewan direksi berpengaruh negatif signifikan terhadap manajemen laba. Sedangkan ukuran perusahaan dan pertumbuhan perusahaan berpengaruh positif signifikan terhadap manajemen laba.
\end{abstract}

Coresponden author:

Email: shandd2621@gmail.com
Board

Characteristics;

Earnings

Management;

Audit Committee

Characteristics

\section{Pendahuluan}

Pendahuluan Laporan keuangan memberikan informasi tentang kinerja suatu perusahaan serta menunjukkan laba atau penghasilan perusahaan tersebut. Laba atau penghasilan perusahaan yang meningkat dan baik dapat menggambarkan suatu keberhasilan serta meningkatnya nilai perusahaan tersebut. Tetapi peningkatan laba pada laporan keuangan yang dilaporkan terkadang tidak sesuai dengan pertumbuhan perusahaan yang sebenarnya. Hal ini dikarenakan keputusan yang telah diambil oleh manajemen perusahaan (Rajeevan \& Ajward, 2019).

Keputusan yang telah diambil oleh manajemen perusahaan tersebut adalah dengan memanipulasi informasi laporan keuangan yang dikenal sebagai manajemen laba. Manajemen laba merupakan salah satu proses dimana manajer sebuah perusahaan memanipulasi atau mengurangi kualitas laba yang akan dilaporkan dengan tujuan agar dapat sesuai dengan target yang telah ditentukan tetapi tidak sesuai dengan kinerja ekonomi perusahaan yang sebenarnya kepada para pemangku yang berkepentingan demi mendapatkan keuntungan pribadi dan juga sebagai daya tarik investor (Kapoor \& Goel, 2017).

Dalam hal membatasi atau pencegahan terhadap manajemen laba yang dilakukan oleh seorang manajer perusahaan maka adanya karakteristik dewan. Karaktertistik dewan merupakan bagian terpenting dalam struktur atau tata kelola sebuah perusahaan dan pemerintahan. Dewan yang bekerja dengan efesien dan baik maka akan menghasilkan laba perusahaan yang positif (Rajeevan \& Ajward, 2019).

Dewan direktur bertanggung jawab atas semua keputusan yang telah diambil oleh manajemen perusahaan seperti dalam hal jika keputusan yang diambil atau dibuat tidak meningkatkan laba atau memakmisalkan kekayaan bagi pemegang saham melainkan membuat skandal perusahaan sehingga dapat merusak nama baik perusahaan tersebut (Kapoor \& Goel, 2017). Dewan direktur independen dapat melaksanakan tugasnya dengan baik seperti melakukan pengawasan dan juga memastikan semua keputusan yang dihasilkan agar tetap mengutamakan kepentingan seluruh pemegang saham perusahaan tersebut. Hal ini dilakukan untuk mencapai kepentingan bersama serta berusaha untuk menghindari perilaku oportunistik, sehingga kinerja perusahaan dapat meningkat (Dwi Lusi Tyasing Swastika, 2013). 
Kinerja perusahaan dapat meningkat dan menghasilkan kualitas laba yang bagus dipengaruhi oleh frekuensi pertemuan rapat yang dilakukan serta jumlah independensi dewan dan komite audit yang juga lebih tinggi. Kualitas laba yang bagus ternyata tidak hanya karena pengaruh karakteristik dewan saja tetapi banyak peneliti terdahulu menemukan bahwa pembentukan komite audit independen juga dapat membatasi manajemen laba (Kapoor \& Goel, 2017).

Kehadiran komite audit bertanggung jawab dalam hal mengawasi proses akuntansi, transparansi, audit dan pelaporan keuangan untuk memastikan bahwa laporan tersebut menggambarkan kinerja aktual perusahaan yang sebenarnya dalam membatasi manajemen laba. Pembentukan komite audit sangat didukung karena dapat meningkatkan kepercayaan publik dan kredibilitas yang diberikan lebih besar pada laporan keuangan yang dilaporkan (Mishra \& Malhotra, 2016).

Dalam memenuhi peningkatan kepercayaan publik serta kepercayaan yang diberikan lebih besar pada laporan keuangan, maka terjadilah penipuan laporan keuangan atau memanipulasi laba perusahaan karena tekanan tersebut. Penipuan ini membuat para pemegang saham memaksa manajemen perusahaan bertanggung jawab atas keputusan dalam menggunakan manajemen laba yang merusak nilai entitas dan tidak menampilkan kinerja yang sebenarnya (Rajeevan \& Ajward, 2019). Seperti kasus yang terjadi pada agustus 2018 di Indonesia, seorang dewan dan juga selaku komite audit diketahui mempunyai saham dan tidak mengakui kepemilikan saham LPCK tersebut. Berdasarkan aturan perusahaan LPCK, seorang dewan dan juga selaku komite audit dilarang untuk mempunyai saham perusahaan. Hal ini dikarenakan dapat mempengaruhi laba perusahaan pada laporan keuangan yang dilaporkan(Wareza, 2018).

Oleh karena itu, penelitian ini dilakukan dalam hal mengetahui hubungan antara karakterisktik dewan terhadap manajemen laba. Penelitian ini dilakukan pada perusahaan yang tercatat di Bursa Efek Indonesia (BEI) yang mencakup laporan tahunan dari periode 2015 hingga 2019 kecuali perusahaan dibidang asuransi, keuangan dan lembaga perbankan. Hal ini dikarenakan ketatnya regulasi dan peraturan yang diatur serta metode akuntansi yang diikuti beragam untuk laporan keuangan tahunan. Peneliti mengurangi salah satu variabel independen dari jurnal utama yaitu CEO-Chariman Duality, variabel ini tidak dapat diteliti di Indonesia karena seorang direksi tidak dapat merangkap menjadi seorang komisaris juga dan variabel ini hanya berlaku di luar negeri.

\section{Studi Literatur \\ Ukuran Dewan dan Manajemen laba}

Ukuran dewan diukur dari jumlah dewan direksi dalam suatu perusahaan. Ukuran dewan perusahaan yang besar dapat membuat para dewan susah untuk bekerja secara efisien dan efektif. Hal ini merupakan alasan agar dewan perusahaan tetap kecil dikarenakan bahwa ukuran dewan yang besar menghasilkan pelaporan keuangan dengan kualitas laba yang lebih rendah dan tidak menghasilkan nilai entitas yang baik. Maka menjelaskan bahwa ukuran dewan dalam perusahaan mempunyai pengaruh positif terhadap manajemen laba (Kapoor \& Goel, 2017). Hasil penelitian ini didukung juga oleh (Buertey et al., 2020), (Triki Damak, 2018) dan (Abdullah \& Ismail, 2016).

Ukuran dewan perusahaan yang lebih kecil atau semakin rendah dapat bekerja secara efisien dan efektif sehingga menghasilkan nilai yang baik bagi para pemegang saham dan juga dapat mempertahankan tingkat kualitas laba yang tinggi dalam pelaporan keuangan. Ukuran dewan yang kecil juga dapat mengurangi manipulasi laba perusahaan. Maka menjelaskan bahwa ukuran dewan direksi mempunyai pengaruh negatif terhadap manajemen laba (Aygun et 
al., 2014). Hasil penelitian ini juga didukung oleh (Alareeni, 2018), (Sial et al., 2019), (Rajeevan \& Ajward, 2019) dan (Saona et al., 2020).

$\mathbf{H}_{1}$ : Ukuran dewan direksi berpengaruh negatif terhadap manajemen laba.

\section{Dewan Independensi dan Manajemen laba}

Dewan Independensi harus bekerja dan melaksanakan tanggung jawabnya secara independen. Dalam penelitian di Indonesia menemukan bahwa dewan independensi berpengaruh negatif terhadap manajemen laba. Hal ini menjelaskan semakin tinggi proporsi dewan independensi pada dewan direksi maka lebih baik karena dapat mencegah manipulasi laba yaitu manajemen laba (Dwi Lusi Tyasing Swastika, 2013). Hal ini juga didukung oleh (Abdullah \& Ismail, 2016) dan (Kapoor $\&$ Goel, 2017). Sebaliknya jika terjadinya tidak signifikan antara dewan independensi dan manajemen laba maka hal tersebut dikarenakan dewan direksi perusahaan tidak independen secara substansi (Abdullah \& Ismail, 2016).

$\mathbf{H}_{2}$ : Ukuran dewan independensi berpengaruh negatif terhadap manajemen laba.

Rapat Dewan dan Manajemen laba

Jumlah rapat dewan ditemukan mempunyai dampak positif terhadap manajemen laba. Hal ini menjelaskan bahwa rapat dewan bermanfaat dalam pemantauan manajamen yang efektif yang menyebabkan berkurangnya praktik manajemen laba seperti dalam hal pembahasan, implementasi strategi dan dapat berbagi pendapat atau konsultasi bersama untuk menyelesaikan masalah ataupun mencapai target. Dengan kata lain, semakin banyak pertemuan rapat dewan dilakukan maka banyak masalah terkait dengan perusahaan tersebut (Wan Masliza Wan Mohammad, Shaista Wasiuzzaman, 2016). Hal ini juga didukung oleh (Rajeevan \& Ajward, 2019).

$\mathbf{H}_{\mathbf{3}}$ : Rapat dewan berpengaruh positif terhadap manajemen laba.

\section{Keahlian Dewan dan Manajemen laba}

Keahlian dewan adalah ukuran dewan direktur dengan sertifikasi keahlian dibidang keuangan akuntansi. Beberapa penelitian menemukan bahwa jumlah keahlian dewan ini dapat membuat manajemen laba menjadi lebih rendah. Maka menjelaskan bahwa adanya pengaruh positif antara keahlian dewan dan manajemen laba (Rajeevan \& Ajward, 2019). Tetapi ada juga peneliti yang mengurangi variabel keahlian dewan ini dari model penelitian untuk mengurangi masalah multikolinearitas (Sun et al., 2014).

$\mathbf{H}_{4}$ : Keahlian dewan direksi berpengaruh positif terhadap manajemen laba.

\section{Ukuran Komite dan Manajemen laba}

Ukuran komite dapat tidak memiliki efek sama sekali terhadap manajemen laba, hal ini ditemukan dalam penelitian di Indonesia dengan judul tata kelola perusahaan terhadap manajemen laba. Keberadaannya penting karena pada saat menangani pengendalian masalah menjadi sarana penghubung antara dewan komisaris dan seorang investor dengan pihak manajemen, tetapi tidak ada pengaruh dengan manajemen laba perusahaan. Sehingga ini menjelaskan ukuran komite audit berpengaruh signifikan terhadap manejemen laba (Sutino \& Khoiruddin, 2016). Ukuran komite harus mempunyai ukuran yang cukup untuk pembagian tugas yang perlu dikerjakan oleh komite audit dan meningkatkan kinerja entitas (Agyei-Mensah \& Yeboah, 2019).

$\mathbf{H}_{5}$ : Ukuran komite audit berpengaruh negatif terhadap manajemen laba.

\section{Komite Audit Independensi dan Manajemen laba}

Komite audit independensi ditemukan mempunyai signifikan negatif terhadap manajemen laba perusahaan, hal ini dikarenakan bahwa keberadaan komite audit independensi merupakan salah satu variabel dalam tata kelola perusahaan yang baik dan sangat membantu dalam membatasi serta mengurangi tindakan manajemen laba perusahaan (Pramithasari \& Yasa, 2017). Dalam 
penelitian dalam perusahaan di Spanyol menunjukkan bahwa komite audit yang lebih independen dapat mendorong berkurangnya atau lebih sedikit terjadinya manipulasi pendapatan. Komite audit independensi dapat dikatakan sebagai faktor kunci untuk meningkatkan dalam hal pencegahan terjadinya salah saji dalam pernyataan laporan keuangan. Pengaruh negatif ini juga di dukung oleh (AgyeiMensah \& Yeboah, 2019) dan (Saona et al., 2020).

$\mathbf{H}_{6}$ : Ukuran komite audit independensi berpengaruh negatif terhadap manajemen laba.

\section{Rapat Komite Audit dan Manajemen laba}

Jumlah rapat pertemuan komite audit bisa menunjukkan komite audit yang aktif ataupun tidak aktif dalam memantau manajemen secara efektif. Beberapa penelitian menemukan bahwa rapat komite audit bersignifikan negatif terhadap manajemen laba karena komite audit setiap perusahaan bertemu paling sedikit 4 (empat) kali per tahunnya, serta frekuensi rapat mempunyai peran dalam mengurangi tindakan manajemen laba (Agyei-Mensah \& Yeboah, 2019). Salah satu penelitian yang dilakukan di India menjelaskan ketika komite audit sering melakukan rapat maka kesempatan yang dimiliki lebih besar untuk membahas masalah dalam pelaporan keuangan perusahaan dan lebih efektif mencegah terjadinya penipuan laporan keuangan (Mishra \& Malhotra, 2016).

$\mathbf{H}_{\mathbf{7}}$ : Rapat komite audit berpengaruh negatif terhadap manajemen laba.

\section{Keahlian Komite Audit di Bidang Keuangan dan Akuntansi terhadap Manajemen laba}

Keahlian komite audit di bidang finansial dan akuntansi berdampak baik terhadap manajemen laba, ini menjelaskan bahwa walaupun komite audit bisa menambah keahlian dalam memantau manajemen laba riil, dampak positif ini dikatakan lebih lemah jka dibandingkan dengan efek negatifnya dari peningkatan kesibukkan dan menghambat pendeteksian manajemen laba riil (Sun et al., 2014). Hal ini juga didukung oleh (Agyei-Mensah \& Yeboah, 2019) dan (Rajeevan \& Ajward, 2019).

$\mathbf{H}_{\mathbf{8}}$ : Ukuran keahlian komite audit di bidang keuangan dan akuntansi berpengaruh negatif terhadap manajemen laba.

\section{Metode Penelitian}

Teknik purposive sampling digunakan dalam hal mengumpulkan sampel berdasarkan kriteria yang dapat diambil untuk penelitian ini (Pramithasari \& Yasa, 2017). Informasi data sampel yang digunakan yakni laporan keuangan tahunan perusahaan yang sudah terdaftar dalam list perusahaan BEI tahun 2015-2019 berjumlah 399 perusahaan dan tidak termasuk perusahaan asuransi, keuangan dan lembaga perbankan. Informasi yang diperlukan dapat diunduh atau dilihat langsung di website resmi IDX. Penelitian ini menerapkan teknik studi pustaka yang berarti diperoleh dari kertas kerja yang mempunyai hubungan dengan topik yang sedang diteliti, serta dengan teknik dokumentasi yang berarti data yang didapatkan melalui laporan keuangan tahunan suatu perusahaan sudah memenuhi syarat atau kriteria yang diperlukan dalam membuktikan hal seberapa kesenjangan data-data yang dikumpulkan.

Pengolahan data dikumpulkan menggunakan dua software yaitu SPSS dan Eviews 10. Penelitian ini menggunakan metode regresi data panel. Data panel berarti gabungan dari cross section dengan time series (Rajeevan \& Ajward, 2019). Penelitian ini menggunakan SPSS untuk menguji data deskriptif dan juga uji data outlier, kemudian dilanjutkan dengan penggunaan software Eviews 10 untuk menentukan model terbaik dengan uji Chow dan uji Hausman, uji F, uji t, dan uji Adjusted $\mathrm{R}^{2}$. 


\section{Definisi Operasional Variabel Variabel Dependen}

Manajemen laba riil atau Real earnings management merupakan variable dependen yang diukur dengan tiga proksi yakni; manipulasi berbasis penjualan (arus kas abnormal), berbasis biaya diskresioner (abnormal) serta berbasis biaya produksi (biaya produksi abnormal) (Rajeevan \& Ajward, 2019).

\section{Arus kas abnormal}

Arus kas abnormal merupakan manipulasi penjualan atau laba yang berarti bahwa seorang manajer sebuah perusahaan berusaha untuk meningkatkan penjualan sementara pada tahun tersebut dengan menawarkan harga diskon atau persyaratan kredit yang lebih lunak (Sun et al., 2014).

\section{Biaya diskresioner abnormal}

$$
\mathrm{CFO}_{\mathrm{t}}: \mathrm{Ta}_{\mathrm{t}-1}=\mathrm{a}_{0}\left(1: \mathrm{TA}_{\mathrm{t}-1}\right)+\mathrm{a}_{1}\left(\operatorname{SALES}_{\mathrm{t}}: \mathrm{T}_{\mathrm{t}-1}\right)+\mathrm{a}_{2}\left(\Delta \operatorname{SALES}_{\mathrm{t}}: \mathrm{TA}_{\mathrm{t}-1}\right)+\varepsilon
$$

Biaya diskresioner abnormal merupakan seorang manajer sebuah pihak perusahaan yang mengurangi pengeluaran diskresioner seperti biaya periklanan, biaya penjualan, biaya R\&D, umum dan biaya administrasi untuk peningkatan laba atau pendapatan (Sun et al., 2014).

\section{Biaya produksi abnormal}

$$
\operatorname{DISX}_{\mathrm{t}}: \mathrm{TA}_{\mathrm{t}-1}=\mathrm{a}_{0}\left(1: \mathrm{TA}_{\mathrm{t}-1}\right)+\mathrm{a}_{1}\left(\operatorname{SALES}_{\mathrm{t}-1}: \mathrm{TA}_{\mathrm{t}-1}\right)+\varepsilon
$$

Biaya produksi abnormal merupakan seorang manajer sebuah perusahaan meningkatkan laba dengan cara memproduksi barang lebih banyak unit dari biasanya atau dari yang diperlukan untuk menurunkan biaya tetap per unitnya dan setelah itu harga pokok penjualan(Sun et al., 2014).

PROD $_{\mathrm{t}}: \mathrm{TA}_{\mathrm{t}-1}=\mathrm{a}_{0}\left(1: \mathrm{TA}_{\mathrm{t}-1}\right)+\mathrm{a}_{1}\left(\operatorname{SALES}_{\mathrm{t}}: \mathrm{TA}_{\mathrm{t}-1}\right)+\mathrm{a}_{2}\left(\Delta\right.$ SALES $\left._{\mathrm{t}}: \mathrm{TA}_{\mathrm{t}-1}\right)+\mathrm{a}_{3}\left(\Delta\right.$ SALES $\left._{\mathrm{t}}: \mathrm{TA}_{\mathrm{t}-1}\right)+\varepsilon$

\section{Variabel Independen \\ Ukuran Dewan}

Dewan direksi dengan mayoritas direksi eksternal dinyatakan dapat memberikan pengetahuan yang lebih bagus dan baik bagi organisasi dan berada di tempat yang lebih baik untuk hal dalam mengawasi serta mengatur para manajer perusahaan, sehingga dapat membatasi manajemen laba. Ukuran dewan direksi dapat diukur dengan jumlah dewan direksi pada perusahaan i pada periode $t$ (Rajeevan \& Ajward, 2019).

\section{Dewan Independensi}

Dewan independensi dikenal untuk meningkatkan transparansi serta integritas pelaporan keuangan sebuah perusahaan. Dewan perusahaan yang mempunyai banyak dewan independen maka lebih siap untuk melakukan pengawasan yang efektif. Dewan Independen dapat diukur dengan jumlah direktur independen untuk peruasahaan i dan periode $t$ (Kapoor \& Goel, 2017).

\section{Rapat Dewan}

Dewan yang lebih sering mengadakan rapat atau bertemu selama periode gejolak dapat menunjukkan adanya peningkatan kinerja keuangan perusahaan karena jika lebih sering mengadakan rapat maka dapat mengalokasikan lebih banyak waktu untuk membahas masalah-masalah tentang manajemen laba. Rapat dewan diukur dengan jumlah rapat dewan untuk perusahaan $\mathrm{i}$ dan peiode $\mathrm{t}$ (Rajeevan \& Ajward, 2019).

\section{Keahlian Dewan}

Terkait tentang keahlian keuangan dan akuntansi, dapat dibuktikan bahwa terdapat lebih sedikitnya manajemen laba dikarenakan oleh adanya kehadiran direktur non-eksekutif independen di dewan, komite audit, serta pakar akuntansi dan keuangan di komite audit. Keahlian dewan dapat diukur dengan jumlah anggota dengan kualifikasi keuangan dan akuntansi untuk perusahaan i dan periode $t$ (Rajeevan \& Ajward, 2019). 


\section{Ukuran Komite Audit}

Ukuran komite audit yang lebih besar akan meningkatkan peran dalam pemantauannya (Abdullah \& Ismail, 2016). Ukuran komite audit dapat diukur dengan jumlah anggota komite audit dalam perusahaan i dan periode $t$ (Rajeevan $\&$ Ajward, 2019).

\section{Komite Audit Independensi}

Komite audit independensi merupakan komite audit independen perusahaan i pada tahun atau periode $t$ diukur sebagai persentase anggota dewan independen pada komite audit yang telah ditetapkan oleh suatu perusahaan (Triki Damak, 2018).

\section{Rapat Komite Audit}

Menurut tata kelola perusahaan, setiap entitas harus mengadakan rapat setidaknya 3 sampai 4 kali rapat komite audit. Rapat komite audit diukur dengan jumlah rapat komite audit dalam perusahaan i pada periode $t$ (Rajeevan \& Ajward, 2019).

\section{Keahlian Komite Audit di Bidang Keuangan dan Akuntansi}

Keahlian komite audit di bidang keuangan dan akuntansi dapat diukur dengan jumlah anggota dengan kualifikasi bidang keuangan dan/atau akuntansi pada komite audit untuk perusahaan i pada periode t (Rajeevan \& Ajward, 2019).

\section{Varibel Kontrol}

\section{Leverage}

Leverage merupakan ratio total utang terhadap total asset serta merupakan ukuran resiko pelanggaran perjanjian utang (Rajeevan \& Ajward, 2019). Leverage jika dirumuskan menjadi

\section{Big 4}

$$
\text { Leverage }=\text { Total Hutang/Total asset }
$$

Big 4 merupakan KPMG, Ey Ernst \& young, price water house cooper (PWC), dan deloitte. Banyak studi menyatakan bahwa ada persepsi bahwa kredibilitas laporan keuangan organisasi yang lebih tinggi ketika Big 4 perusahaan tersebut memberikan jaminan eksternal atas laporan keuangan (Rajeevan \& Ajward, 2019). Kemudian dapat dirumuskan menjadi:

Big $4=1$

Non-Big4 $=0$

Ukuran Perusahaan

Ukuran perusahaan dapat dijelaskan dengan logaritma yang natural dari hasil penjualan perusahaan i untuk periode $t$ (Rajeevan \& Ajward, 2019).

\section{Growth}

Pertumbuhan atau growth yang diteliti merupakan pertumbuhan penjualan yang diukur dengan perbandingan selisih penjualan pada tahun $t$ dan $t-1$ terhadap penjualan pada t-1 (Le et al., 2020).

\section{Hasil Dan Pembahasan} Hasil Analisis

Pengujian data dilakukan dengan beberapa tahap atau bagian yakni statistic deskriptif, uji Chow, uji Hausman, uji F, uji t, dan uji Adjusted R2. Berikut untuk tabel 1 hasil analisis statistik deskriptif. 
Tabel 1. Analisis Statistik Deskriptif

\begin{tabular}{lcccccc}
\hline & $\mathrm{N}$ & Min & Max & Sum & Mean & Std. Deviation \\
\hline CFOt & 1909 & -11.34 & 25.82 & 1770.01 & 0.93 & 1.35 \\
DISXt & 1909 & -1.70 & 20.42 & 1617.23 & 0.85 & 1.04 \\
PRODt & 1909 & -23.49 & 25.95 & 1731.66 & 0.91 & 1.69 \\
UD & 1909 & 2 & 15 & 9154 & 4.80 & 1.89 \\
DI & 1909 & 0 & 8 & 1458 & 0.76 & 0.58 \\
RD & 1909 & 0 & 81 & 32939 & 17.25 & 12.07 \\
KD & 1909 & 0 & 6 & 961 & 0.50 & 0.86 \\
UKA & 1909 & 0 & 8 & 5764 & 3.02 & 0.55 \\
KAI & 1909 & 0 & 8 & 5570 & 2.92 & 0.76 \\
RKA & 1909 & 0 & 61 & 12129 & 6.35 & 6.48 \\
KKA & 1909 & 0 & 3 & 445 & 0.23 & 0.49 \\
Lev & 1909 & 0.007623153 & 973.41 & 2306.12 & 1.21 & 22.40 \\
UP & 1909 & 7.78 & 14.38 & 23200.89 & 12.15 & 0.86 \\
Growth & 1909 & 1.791085813 & 67.43 & 460.03 & 0.24 & 2.48 \\
\hline
\end{tabular}

Sumber: Data sekunder yang diambil, 2021

Pada tabel 1 menunjukkan hasil dari uji statistik deskriptif dalam penelitian ini. Nilai rata-rata dari model untuk variabel dependen manajemen laba yakni CFOt, DISXt, PRODt menunjukkan nilai 0.93, 0.85 dan 0.91 yang dimana dengan nilai standar deviasinya 1.35, 1.04 dan 1.69 dari nilai hasil yang diuji tersebut menunjukkan hasil yang sangat tinggi dan juga menjelaskan bahwa manajeman laba perusahaan di Indonesia mempunyai pengaruh yang luas.

Pada variabel ukuran dewan direksi pada satu perusahaan paling sedikit ada 2 direksi dan paling banyak ada 15 orang sehingga rata-rata ukuran dewan direksi pada suatu perusahaan di Indonesia sebanyak empat orang agar dapat terbagi semua pekerjaaan direksi dengan nilai standar deviasi 1.89. Untuk dewan independen direksi paling banyak ada 4 orang pada perusahaan yang besar dan sudah terkenal lama berdiri sedangkan untuk perusahaan kecil tidak begitu mementingkan adanya dewan indepeden ini. Sehingga rata-rata dewan independensi pada perusahaan di Indonesia 0.71 dengan nilai standar deviasi 0.46 .

Rapat dewan direksi yang diadakan oleh perusahaan paling banyak dilakukan sebanyak 81 kali pertemuan untuk membahas semua kinerja dan masalah perusahaan. Nilai standar deviasi rapat dewan direksi adalah 17.25 dengan nilai rata-rata 12.07. Keahlian dewan direksi yang mempunyai gelar sertifikasi sangatlah jarang ditemukan dijabatan ini dengan hasil nilai paling banyak 6 orang dengan nilai rata-rata 0.50 karena walaupun tidak mempunyai gelar sertifikasi tetap saja bisa menjabat sebagai seorang direktur atau direktur utama pada perusahaan besar. Nilai standar deviasi keahlian dewan direksi adalah 0.86 .

Ukuran komite audit dan komite audit independen masing-masing paling banyak dengan 8 orang pada suatu perusahaan dengan hasil rata-rata 3.02 dan 2.92 karena banyak komite audit atau hampir semua perusahaan mewajibkan untuk dapat bekerja secara independen agar tugas yang dikerjakan menjadi lebih baik dan bagus. Untuk variabel keahlian komite audit sama dengan keahlian dewan direksi sulit untuk didapatkan informasi sertifikasi setiap orangnya karena 
tidak semua perusahaan melampirkan didalam laporan keuangan tahunan dan juga untuk menjabat sebagai komite audit perusahaan tidak diwajibkan untuk mempunyai sertifikasi di bidang keahlian akuntansi. Hasil uji menunjukkan nilai paling banyak 3 orang dengan rata-rata 0.23 dan untuk nilai standar deviasi menunjukkan hasil 0.49 .

Untuk tiga variabel kontrol dalam penelitian ini, yang pertama ada leverage menunjukkan nilai rata-ratanya 1.21 dan nilai standar deviasi sebesar 22.40. kemudian yang kedua ada ukuran perusahaan dengan nilai minimum 7.78 dan maximum 14.38 serta nilai standar deviasi 0.86 . Lalu dilanjutkan dengan dengan variabel terakhir yaitu growth dengan nilai min -1.791, max 67.43 dengan nilai standar deviasi 2.48 .

\begin{tabular}{lrrrr}
\multicolumn{5}{c}{ Tabel 2. Frekuensi Variabel Dummy } \\
\hline & Frekuensi & Persentase & Validasi\% & Kumulatif\% \\
\hline Non-Big4 & 1204 & 63.1 & 63.1 & 63.1 \\
Big4 & 705 & 36.9 & 36.9 & 100.0 \\
Total & 1909 & 100 & 100 & \\
\hline
\end{tabular}

Sumber: Data sekunder diolah, 2021

Pada tabel hasil uji variabel dummy menunjukkan frekuensi perusahaan yang Non-Big4 lebih banyak dibandingkan perusahaan yang sudah diaudit oleh Big4. Nilai non-big4 mempunyai nilai frekuensi sebesar 1204 sedangkan untuk big4 sebesar 705 . Jika dijelaskan dalam bentuk persentase maka Non-big4 menunjukkan hasil 63\% dan yang Big4 menunjukkan hasil 37\% dari data yang diuji.

Dalam proses penelitian, hasil uji outlier menjelaskan bahwa ada sejumlah data yang tidak dapat diuji karena mempunyai sifat tidak normal sehingga harus dihapus dari data yang diuji agar tidak mempengaruhi hasil uji data sampel. Yang dimana dalam penelitian ini terdapat 16 data yang bersifat tidak wajar sehingga data tersebut terpaksa harus dihapus yang menghasilkan sisa data yang dapat diuji hanyalah 1909 data.

Regresi panel merupakan pengujian dengan beberapa pilihan model yang bisa diuji untuk memilih hasil akhir dari model tersebut mana yang menunjukkan model yang terbaik dan cocok digunakan dalam penelitian ini yang diantaranya ada Pooled Least Squared (PLS), Fixed Effect Model (FEM), Random Effect Model (REM). Untuk pemilian model tersebut tergantung pada nilai hasil uji chow, yang kemudian akan dilanjutkan lagi dengan hasil uji housman lagi dalam penelitian ini demi memilih model yang sesuai.

\begin{tabular}{lc} 
Hasil Uji Chow & \\
\hline Cross-section Tes Efek & Prob. \\
\hline Chi-square CFOt & 0.0000 \\
Chi-square DISXt & 0.0000 \\
Chi-square PRODt & 0.0000 \\
\hline
\end{tabular}

Sumber: Data sekunder diolah, 2021

Dari tabel 3 bisa diketahui bahwa variabel manajemen laba rill dengan model yang terdahulu yakni 3 pengukuran Cfopt, Disxt, dan Prodt masing-masing dengan nilai probabilitas 0.0000. Disini menunjukkan bahwa nilai Cfopt, Disxt, dan Prodt tersebut <0.05 sehingga model FEM dapat digunakan yang kemudian harus dilanjutkan lagi dengan uji housman untuk menentukan model yang cocok. 
Tabel 4. Uji Housman

Hasil Uji Housman

\begin{tabular}{lc}
\hline Test Summary & Prob. \\
\hline Cross-section random CFOt & 0.0041 \\
Cross-section random DISXt & 0.0004 \\
Cross-section random PRODt & 0.0013 \\
\hline
\end{tabular}

Sumber: Data sekunder diolah, 2021

Dari tabel 4 dapat diketahui bahwa variabel manajemen laba rill dengan model yang terdahulu yakni 3 pengukuran Cfopt, Disxt, dan Prodt masing-masing dengan nilai $0.0041,0.0004$ dan 0.0013. Disini menunjukkan bahwa nilai tersebut $<0.05$ sehingga model FEM dapat digunakan dan merupakan model terbaik untuk model penelitian ini.

\begin{tabular}{lc} 
Hasil Uji F & \\
\hline Variabel Dependen & Prob. \\
\hline Prob(F-statistic) CFOt & 0.0000 \\
Prob(F-statistic) DISXt & 0.0000 \\
Prob(F-statistic) PRODt & 0.0000 \\
\hline
\end{tabular}

Sumber: Data sekunder diolah, 2021

Dari tabel 5 menunjukkan bahwa semua nilainya 0.000000 yang berarti variabel independen mempunyai hubungan atau signifikan terhadap varianel dependen yang diuji karena nilainya lebih kecil dari 0.005 .

Tabel 6. Uji T untuk CFOt

\begin{tabular}{lrc}
\multicolumn{2}{l}{ Hasil Uji CFOt } & \\
\hline \multicolumn{1}{c}{ Variabel } & Koefisien & Prob. \\
\hline Konstan & -9.8941 & 0.0000 \\
UD & 0.0241 & 0.5215 \\
DI & -0.0974 & 0.4595 \\
RD & 0.0011 & 0.8234 \\
KD & 0.0437 & 0.6621 \\
UKA & -0.0210 & 0.8993 \\
KAI & -0.0179 & 0.9031 \\
RKA & -0.0073 & 0.5004 \\
KKA & 0.1762 & 0.1919 \\
Lev & 0.0008 & 0.5121 \\
BIG4 & 0.0243 & 0.9067 \\
UP & 0.8914 & 0.0000 \\
Growth & 0.0623 & 0.0000 \\
\hline
\end{tabular}

Sumber: Data sekunder diolah, 2021

Dari hasil uji T pada tabel 6, variabel ukuran perusahaan menunjukkan hubungan positif terhadap manajemen laba rill dan juga dibuktikan oleh beberapa peneliti lainnya yakni Rajeevan \& Ajward (2019), Aygun et al., (2014), Le et al., (2020), Triki Damak (2018), Lisboa (2016), Kim \& Yang (2014), Kouaib et al., (2018), 
Gunawan, Rahmat, Tjahjadi (2018), Wan Masliza Wan Mohammad, Shaista Wasiuzzaman (2016). Dan yang terakhir variabel growth mempunyai hubungan positif terhadap manajemen laba riil dan juga dibuktikan oleh peneliti lainnya yakni Rajeevan \& Ajward (2019), Borralho et al., (2020), Le et al., (2020).

Tabel 7. Uji T untuk DISXt

\begin{tabular}{lrc}
\multicolumn{2}{l}{ Hasil Uji DISXt } & \\
\hline \multicolumn{1}{c}{ Variabel } & Koefisien & Prob. \\
\hline Konstan & 1.1156 & 0.1206 \\
UD & -0.0485 & 0.0091 \\
DI & 0.0013 & 0.9839 \\
RD & -0.0004 & 0.8694 \\
KD & 0.0621 & 0.2081 \\
UKA & 0.0010 & 0.9904 \\
KAI & -0.0077 & 0.9150 \\
RKA & -0.0021 & 0.6969 \\
KKA & 0.0587 & 0.3783 \\
Lev & 0.0006 & 0.3324 \\
BIG4 & 0.0213 & 0.8356 \\
UP & -0.0040 & 0.9455 \\
Growth & -0.0082 & 0.1215 \\
\hline
\end{tabular}

Sumber: Data sekunder diolah, 2021

Dari hasil uji T pada tabel 7 membuktikan bahwa ukuran dewan direksi mempunyai pengaruh negatif terhadap manajemen laba riil dan telah dibuktikan oleh beberapa peneliti lainnya yakni Sun et al., (2014), Aygun et al., (2014), Kim \& Yang, (2014), Alareeni, (2018), Sial et al., (2019), Rajeevan \& Ajward, (2019).

Tabel 8. Uji T untuk PRODt Hasil Uji PRODt

\begin{tabular}{lrr}
\hline \multicolumn{1}{c}{ Variabel } & \multicolumn{1}{c}{ Koefisien } & \multicolumn{1}{l}{ Prob. } \\
\hline Konstan & -13.8745 & 0.0000 \\
UD & 0.0044 & 0.9266 \\
DI & -0.2869 & 0.0835 \\
RD & 0.0020 & 0.7577 \\
KD & 0.1104 & 0.3803 \\
UKA & -0.0553 & 0.7907 \\
KAI & -0.0661 & 0.7208 \\
RKA & -0.0110 & 0.4206 \\
KKA & 0.2142 & 0.2077 \\
Lev & 0.0023 & 0.1432 \\
BIG4 & -0.0138 & 0.9578 \\
UP & 1.2556 & 0.0000 \\
Growth & 0.0506 & 0.0002 \\
\hline \multicolumn{3}{l}{ Sumber: Data sekunder diolah, 2021 }
\end{tabular}


Dari hasil uji $\mathrm{T}$ pada tabel 8 menunjukkan hasil kesimpulan yang sama dengan tabel 6. hasil uji pada tabel 6,7 dan 8 menyimpulkan bahwa dewan independen, rapat dewan, keahlian dewan direksi, ukuran komite audit, komite audit independen, rapat komite audit, keahlian komite audit, leverage dan big4 tidak mempunyai hubungan atau tidak signifikan terhadap variabel dependen yang dapat dilihat dari nilai probabilitasnya. Hal ini dikarenakan dewan direksi dan komite audit yang bekerja pada sebagian besar perusahaan di Indonesia tidak independen secara substansi, tidak mementingkan sertifikasi keahlian untuk menentukan kemampuan seseorang dalam bekerja, mempunyai frekuensi rapat yang rendah, serta masih banyak perusahaan yang laporan keuangannya tidak di audit oleh Big4.

Regresi panel persamaan berdasarkan tabel ke 6 dapat diuraikan menjadi: $\mathrm{CFOt}=-9.894108+0.024136 \mathrm{Y} 1-0.097355 \mathrm{Y} 2+0.001137 \mathrm{Y} 3+0.043663 \mathrm{Y} 4-$ $0.020959 \mathrm{Y} 5-0.017882 \mathrm{Y} 6-0.007306 \mathrm{Y} 7+0.176226 \mathrm{Y} 8+0.000822 \mathrm{Y} 9+$ $0.024294 \mathrm{Y} 10+0.891447 \mathrm{Y} 11+0.062345 \mathrm{Y} 12+\mathrm{E}$.

Regresi panel persamaan berdasarkan tabel ke 7 dapat diuraikan menjadi: $\mathrm{DISXt}=1.115643-0.048534 \mathrm{Y} 1+0.001309 \mathrm{Y} 2-0.000414 \mathrm{Y} 3+0.062112 \mathrm{Y} 4+$ $0.000983 \mathrm{Y} 5-0.007742 \mathrm{Y} 6-0.002085 \mathrm{Y} 7+0.05874 \mathrm{Y} 8+0.0006 \mathrm{Y} 9+0.021252$ Y10 - 0.003974 Y11 - 0.008219 Y12 + E.

Regresi panel persamaan berdasarkan tabel ke 8 dapat diuraikan menjadi: $\mathrm{PRODt}=-13.87454+0.004364 \mathrm{Y} 1-0.286883 \mathrm{Y} 2+0.001979 \mathrm{Y} 3+0.110366 \mathrm{Y} 4-$ $0.055345 \mathrm{Y} 5-0.066098 \mathrm{Y} 6-0.010991 \mathrm{Y} 7+0.214154 \mathrm{Y} 8+0.002312 \mathrm{Y} 9-$ $0.013809 \mathrm{Y} 10+1.255622 \mathrm{Y} 11+0.050591 \mathrm{Y} 12+\mathrm{E}$.

Keterangan:

$\mathrm{Y} 1=$ Ukuran dewan direksi/UD

$\mathrm{Y} 2=$ Dewan independent $/ \mathrm{DI}$

$\mathrm{Y} 3=$ Rapat dewan $/ \mathrm{RD}$

$\mathrm{Y} 4=$ Keahlian dewan direksi $/ \mathrm{KD}$

Y5 $=$ Ukuran komite audit/UKA

$\mathrm{Y} 6=$ Komite audit independent/KAI

$\mathrm{Y} 7=$ Rapat komite audit/RKA

$\mathrm{Y} 8=$ Keahlian komite audit $/ \mathrm{KKA}$

$\mathrm{Y9}=$ Leverage

$\mathrm{Y} 10=\mathrm{BIG} 4$

$\mathrm{Y} 11=$ Ukuran perusahaan/UP

$\mathrm{Y} 12=$ Growth

$\mathrm{E}=$ Error

Tabel 9. Uji Koefisien Determinasi

\begin{tabular}{lc}
\hline Variabel Dependen & Adjusted $R$-Squared \\
\hline CFOt & 0.441541 \\
DISXt & 0.770327 \\
PRODt & 0.432453 \\
\hline
\end{tabular}

Sumber: Data sekunder diolah, 2021

Dari tabel 9 menampilkan bahwa nilai pengukuran CFOt sebesar 0.441541, nilai pengukuran DISXt sebesar 0.770327, dan nilai pengukuran PRODt sebesar 0.432453. hal ini membuktikan bahwa ukuran dewan direksi, dewan independen, rapat dewan, keahlian dewan direksi, ukuran komite audit, komite audit independen, rapat komite audit, keahlian komite audit, leverage, big4, ukuran 
perusahaan dan growth dapat menjelaskan atau mempunyai pengaruh keterlibatan terhadap variabel dependen yaitu manajemen laba riil sebesar 44\%, 77\% dan 43\% sedangkan $56 \%$, 23\%, dan 57\% dikarenakan oleh variabel lain ataupun aspek lain yang tidak terlibat dalam penelitian ini.

\section{Kesimpulan dan Saran Kesimpulan}

Berdasarkan semua hasil uji dan analisis yang telah dilakukan, sehingga mendapatkan kesimpulan yang jelas bahwa untuk ukuran dewan direksi mempunyai pengaruh signifikan negatif terhadap manajemen laba riil. Dapat dijelaskan bahwa semakin sedikitnya ukuran dewan direksi pada perusahaan maka dewan akan menghilangkan penggunaannya untuk memanipulasi laba pelaporan keuangan atau dikenal dengan manajemen laba. Kemudian untuk ukuran perusahaan dan growth mempunyai pengaruh signifikan positif terhadap manajemen laba riil. Sedangkan untuk variabel dewan independen, rapat dewan, keahlian dewan direksi, ukuran komite audit, komite audit independen, rapat komite audit, keahlian komite audit, leverage dan big4 tidak mempunyai hubungan atau tidak signifikan terhadap variabel dependen yang dapat dilihat dari nilai probabilitasnya.

\section{Saran}

Saran yang di rekomendasikan untuk peneliti selanjutnya untuk meneliti lebih lanjut tahun-tahun yang baru kedepannya untuk mengetahui apakah akan ada terjadinya perubahan signifikan karakteristik para dewan di Indonesia terhadap manajemen laba perusahaan. Kemudian peneliti juga bisa menambahkan beberapa variabel baru yang berkaitan dengan topik ini untuk menambah wawasan yang lebih luas lagi.

\section{Keterbatasan}

Dalam proses penelitian ini, peneliti menyadari bahwa penelitian ini mempunyai keterbatasan yang pertama, hanya fokus meneliti perusahaan yang tercatat dalam Bursa Efek Indonesia (BEI) mulai dari tahun 2015 hingga tahun 2019. Ada beberapa perusahaan pada tahun tertentu tidak konsisten dalam mempublikasikan laporan keuangan dan tahunannya sehingga data yang didapatkan menjadi berkurang. Selain itu, ada dua variabel independen yang membutuhkan profil sertifikasi setiap dewan direksi dan komite audit dalam suatu perusahaan, akan tetapi mayoritas perusahaan tidak melampirkan itu pada laporan keuangan tahunan mereka sehingga informasi tersebut sulit didapatkan oleh peneliti.

\section{Daftar Pustaka}

Abdullah, S. N., \& Ismail, K. N. I. K. (2016). Women directors, family ownership and earnings management in Malaysia. Asian Review of Accounting, 24(4), 525550. https://doi.org/10.1108/ARA-07-2015-0067

Agyei-Mensah, B. K., \& Yeboah, M. (2019). Effective audit committee, audit quality and earnings management: Evidence from the Ghana Stock Exchange. International Journal of Managerial and Financial Accounting, 11(2), 93-112. https: / / doi.org/10.1504/IJMFA.2019.099765

Alareeni, B. (2018). Does corporate governance influence earnings management in listed companies in Bahrain Bourse? Journal of Asia Business Studies, 12(4), 551-570. https: //doi.org/10.1108/JABS-06-2017-0082

Aygun, M., Ic, S., \& Sayim, M. (2014). The Effects of Corporate Ownership Structure and Board Size on Earnings Management: Evidence from Turkey. International Journal of Business and Management, 9(12), 123-132. 
https: / / doi.org/10.5539/ijbm.v9n12p123

Buertey, S., Sun, E. J., Lee, J. S., \& Hwang, J. (2020). Corporate social responsibility and earnings management: The moderating effect of corporate governance mechanisms. Corporate Social Responsibility and Environmental Management, 27(1), 256-271. https://doi.org/10.1002/csr.1803

Dwi Lusi Tyasing Swastika, D. L. T. S. (2013). Corporate Governance, Firm Size, and Earning Management: Evidence in Indonesia Stock Exchange. IOSR Journal of Business and Management, 10(4), 77-82. https: / / doi.org/10.9790/487x-1047782

Kapoor, N., \& Goel, S. (2017). Board Characteristics, Firm Profitability and Earnings Management: Evidence from India. Australian Accounting Review, 27(2), 180-194. https://doi.org/10.1111/auar.12144

Le, H. T. M., Kweh, Q. L., Ting, I. W. K., \& Nourani, M. (2020). CEO power and earnings management: Dual roles of foreign shareholders in Vietnamese listed companies. International Journal of Finance and Economics, December 2018, 117. https://doi.org/10.1002/ijfe.2211

Mishra, M., \& Malhotra, A. K. (2016). Audit Committee Characteristics and Earnings Management: Evidence from India. International Journal of $\begin{array}{llll}\text { Accounting } \text { Financial } & \text { Reporting, }\end{array}$ https: / / doi.org/ 10.5296/ijafr.v6i2.10008

Pramithasari, A. A. P. K., \& Yasa, G. W. (2017). The effect of good corporate governance on earnings management in companies that perform IPO. The Indonesian Accounting Review, 6(1), 37. https://doi.org/10.14414/tiar.v6i1.851

Rajeevan, S., \& Ajward, R. (2019). Board characteristics and earnings management in Sri Lanka. Journal of Asian Business and Economic Studies, 27(1), 2-18. https://doi.org/10.1108/jabes-03-2019-0027

Saona, P., Muro, L., \& Alvarado, M. (2020). How do the ownership structure and board of directors' features impact earnings management? The Spanish case. Journal of International Financial Management and Accounting, 31(1), 98-133. https://doi.org/10.1111/jifm.12114

Sial, M. S., Chunmei, Z., \& Khuong, N. V. (2019). Do female and independent directors explain the two-way relationship between corporate social responsibility and earnings management of Chinese listed firms? International Journal of Accounting and Information Management, 27(3), 442-460. https:/ / doi.org/10.1108/IJAIM-03-2018-0027

Sun, J., Lan, G., \& Liu, G. (2014). Independent audit committee characteristics and real earnings management. Managerial Auditing Journal, 29(2), 153-172. https: / / doi.org/10.1108/MAJ-05-2013-0865

Sutino, E. R. D., \& Khoiruddin, M. (2016). Pengaruh Good Corporate Governance terhadap Manajemen Laba pada Perusahaan yang Masuk dalam JII (Jakarta Islamic Index) Tahun 2012-2013. Management Analysis Journal, 5(3), 156166.

Triki Damak, S. (2018). Gender diverse board and earnings management: evidence from French listed companies. Sustainability Accounting, Management and Policy Journal, 9(3), 289-312. https://doi.org/10.1108/SAMPJ-08-2017-0088

Wan Masliza Wan Mohammad, Shaista Wasiuzzaman, N. M. Z. N. S. (2016). Corporate Governance: The International Journal of Business in Society Article information: Board and Audit Committee effectiveness, Ethnic diversification and Earnings Management: A Study of the Malaysian Manufacturing Sector. The International Journal of Business in Society, 16(4), 726-746. 
Wareza, M. (2018). Punya Saham LPCK, Mantan Komisaris Dihukum OJK. CNBC Indonesia. https://www.cnbcindonesia.com/market/20180910114610-1732442/punya-saham-lpck-mantan-komisaris-dihukum-ojk 